Vietnam Journal of Mechanics, VAST, Vol. 27, No. 3 (2005), pp. 149-157

\title{
USING METIS MODEL TO SOLVE THE TORSION PROBLEM OF A PRISMATIC BAR
}

\author{
${ }^{1}$ Nguyen Tien Duong, ${ }^{2}$ Nguyen Dang Hung \\ ${ }^{1}$ Hanoi University of Technology, Vietnam \\ ${ }^{2}$ University of Lige, Belgium
}

\begin{abstract}
Based on Lekhnitskiis elasticity theory [1], the formulae of generalized plane strain state for the torsion problem of a prismatic bar are established. By this way, this problem in 3 dimensions (3D) is transformed into the problem in $2.5 \mathrm{D}$. Metis models [3] constitute a bridge between the classical models in one field and the hybrid models in two fields. They have the advantage properties of two parents: the dual and monotonous properties of the pure models and the fast convergence of hybrid models. This paper uses the metis displacement model to solve the torsion problem of a prismatic bar after transform this problem from 3D into 2.5D. The agreement of the results in this method with those in exact solution by the analytical method indicated the exactitude of this new model.
\end{abstract}

\section{INTRODUCTION}

The classical (pure displacement and pure equilibrium) models have the dual properties and monotonic convergence very interesting. But the convergence of these models is very slowly. The hybrid displacement and stress models permit the relaxation of the continuity conditions of unknown fields to make easier and more flexible the choice of the hypothesis and the numerical development of the finite elements. The convergence of these models is generally fast but non monotonous. The metis displacement and stress models have the advantage of two parents: the dual and monotonous properties of the pure models and the fast convergence of hybrid models. This paper uses the metis displacement model to solve the torsion problem of a prismatic bar. This problem is transformed to the problem with geometry in 2D by using Lekhitskii's elasticity theory. The metis displacement elements are used to calculate the displacement and stress fields of this problem.

\section{TORSION PROBLEM OF A PRISMATIC BAR}

Consider a prismatic bar of unspecified section, twisted by couples applied at its ends (Fig. 1).

Let the origin of the co-ordinates at the higher end of the bar and suppose that this higher section is prevented from turning; the rotation angle of a cross-section is $\beta=\theta$, where $\theta$ is the unit torsion angle. Saint-Venant supposes that the deformation of the bar consists of:

1. Rotations of the cross-sections with proportional amplitude to their distance to the end fixes;

2. Warping of these sections, which are the same for all the sections.

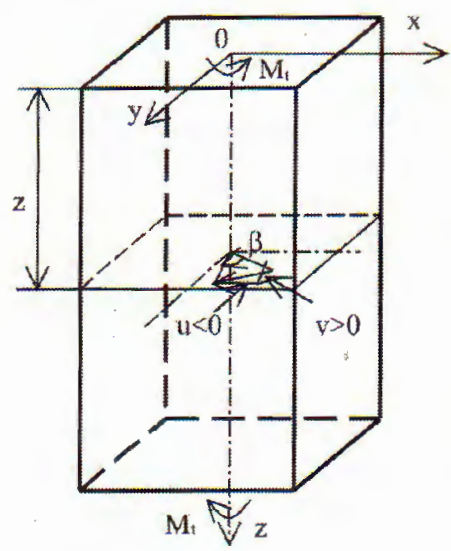

Fig. 1. Prismatic bar torsion 


\subsection{Relations}

\section{ANALYSIS SOLUTION}

The displacements corresponding to this rotation are:

$$
u^{3 D}=-\theta z y ; \quad v^{3 D}=\theta z x,
$$

where: $u^{3 D}$ and $v^{3 D}$ are the displacement components in 3 dimensions.

The warping of the cross-sections is certainly proportional to $\theta$, thus defined by a function of the form:

$$
w^{3 D}=\theta \quad \psi(x, y) .
$$

Using displacements supposed (3.1) and (3.2)., we can calculate the components of the strain, which gives:

$$
\varepsilon_{x}=\varepsilon_{y}=\varepsilon_{z}=\gamma_{x y}=0 ; \gamma_{x z}=\theta\left(\frac{\partial \psi}{\partial x}-y\right) ; \gamma_{y z}=\theta\left(\frac{\partial \psi}{\partial y}+x\right) .
$$

The corresponding components of the stress tensor are:

$$
\sigma_{x}=\sigma_{y}=\sigma_{z}=\tau_{x y}=0 ; \tau_{x z}=G \theta\left(\frac{\partial \psi}{\partial x}-y\right) ; \tau_{y z}=G \theta\left(\frac{\partial \psi}{\partial y}+x\right)
$$

\subsection{Equilateral triangular prismatic bar}

Now consider the torsion of a prismatic bar whose section is an equilateral triangle, according to Solomon [2], the form function is in this case:

$$
\psi=\frac{1}{6 a} y\left(3 x^{2}-y^{2}\right),
$$

where: $a$ is the distance from the orthocentre of equilateral triangle to a side of the triangle.

Introducing (3.5) into (3.4), we obtain:

$$
\begin{aligned}
\tau_{x z} & =\frac{G \theta}{a} y(x-a), \\
\tau_{y z} & =\frac{G \theta}{2 a}\left(x^{2}-y^{2}+2 a x\right) . \quad(b)
\end{aligned}
$$

\section{GENERALIZED PLANE STRAIN STATE OF LEKHNITSKII}

We find simplified solutions of this problem such as in all cross-section, the stress and strain state induced by deformation out of this plan, is independent with the position of the cut plan. This particular state of stress and strain is qualified generalized plane strain state:

$$
\sigma_{i}=\sigma_{i}(x, y) ; \quad \varepsilon_{i}=\varepsilon_{i}(x, y) .
$$

Lekhnitskii [1] suggests that distribution of the normal strain in the direction $z$ is known and imposed by the formula:

$$
\varepsilon_{3}=\varepsilon_{z}=e(x, y) .
$$


This hypothesis allows eliminating the normal stress $\sigma_{z}$ using the third equation of the Hook's law:

$$
\varepsilon_{i}=S_{i j} \sigma_{j} \quad(i, j=1,2, \ldots, 6)
$$

We obtain:

$$
\varepsilon_{\alpha}=S_{\alpha \beta}^{d} \sigma_{\beta}+\tilde{\varepsilon}_{\alpha} \quad(\alpha, \beta=1,2,4,5,6)
$$

where:

$$
S_{\alpha \beta}^{d}=S_{\alpha \beta}-\frac{S_{\alpha 3} S_{3 \beta}}{S_{33}} ; \quad \tilde{\varepsilon}_{\alpha}=e \frac{S_{\alpha 3}}{S_{33}} .
$$

After the integration of the compatibility equations, it gives a reduced form of the displacement field [4]:

$$
\begin{aligned}
& u^{3 D}(x, y, z)=\frac{X_{3} z^{2}}{2}+K_{5} y z+u(x, y) \\
& v^{3 D}(x, y, z)=-\frac{K_{3} z^{2}}{2}-K_{5} x z+v(x, y), \\
& w^{3 D}(x, y, z)=\left(-X_{3} x+K_{3} y+\varepsilon_{3}^{o}\right) z+w(x, y),
\end{aligned}
$$

where: $\varepsilon_{3}^{o}$ is the mean strain; $K_{5}$ is the warping angle; $K_{3}$ is the bending curvature in the plan of weak inertia $O y z ; X_{3}$ is the same quantity in the plan of strong inertia $O x z ; 3 D$ means that 3 dimensions.

The problem is reduced to a $2.5 \mathrm{D}$ problem:

- The geometry is a $2 \mathrm{D}$ domain $\Omega$ with axis $O z$

- The displacement and stress fields are that of the $3 \mathrm{D}$ problem with external loading $\varepsilon_{3}^{o}, K_{3}, X_{3}, K_{5}$ and free traction on the boundary $\partial \Omega$.

From the limited conditions, it leads to solve the following limited problem: Finding $\{\boldsymbol{u}, \boldsymbol{\varepsilon}, \boldsymbol{\sigma}\}$ such that:

$$
\begin{aligned}
& \left.\begin{array}{ll}
\text { (a) } & \varepsilon=S^{d} \sigma+\varepsilon^{o} \\
(b) & \varepsilon=\operatorname{def} u \\
\text { (c) } & \text { equ } \sigma=0
\end{array}\right\} \text { in } \Omega \\
& \text { (d) } \quad \boldsymbol{t}(\sigma)=\mathbf{0} \text { on } \partial \Omega
\end{aligned}
$$

where: def is the partial derivative operator "strain"; equ is the partial derivative operator "equilibrium"; $\mathbf{t}(\boldsymbol{\sigma})$ is the tension on the boundary $\Omega: \mathbf{t}(\boldsymbol{\sigma})=\sigma_{i \alpha} \mathbf{n}_{\alpha}$;

$$
\varepsilon^{o}=\left\{\varepsilon_{1}^{o}, \quad \varepsilon_{2}^{o}, \quad \varepsilon_{4}^{o}, \quad \varepsilon_{5}^{o}, \quad \varepsilon_{6}^{o}\right\}^{T},
$$

with: $\varepsilon_{1}^{o}=\tilde{\varepsilon}_{1} ; \varepsilon_{2}^{o}=\tilde{\varepsilon}_{2} ; \varepsilon_{4}^{o}=\tilde{\varepsilon}_{4}+K_{5} x ; \varepsilon_{5}^{o}=\tilde{\varepsilon}_{5}-K_{5} y ; \varepsilon_{6}^{o}=\tilde{\varepsilon}_{6}$.

\section{CONCEPT OF METIS DISPLACEMENT MODEL}

Let $u^{k}$ be a kinematically admissible displacement field (compatibility within the element and between elements is satisfied). The corresponding total potential energy is:

$$
\Phi\left(\boldsymbol{u}^{k}\right)=\int_{V} V\left(\varepsilon_{i j}^{k}\right) d V-\int_{V} \bar{f}_{i} u_{i}^{k} d V-\int_{S_{\sigma}} n_{j} \bar{\sigma}_{i j} u_{i}^{k} d S,
$$


with the subsidiary condition:

where:

$$
\begin{gathered}
u_{i}=\bar{u}_{i} \text { on } S_{u} \\
\varepsilon_{i j}=\frac{1}{2}\left(u_{i, j}+u_{j, i}\right) \text { in } V ;
\end{gathered}
$$

$V\left(\varepsilon_{i j}^{k}\right)$ - strain encrgy density; $\bar{f}_{i}$ - imposed volume forces; $\bar{t}_{i}=n_{j} \bar{\sigma}_{i j}$ - imposed traction on $S_{\sigma}$.

The pure displacement model is based on the variation of function (5.1). Assumptions are made on the displacement field $u^{k}$ where the requirements of unisolvence are satisfied a priori. Consider the hybrid function of stress:

$$
\Pi\left(\sigma^{e}, u^{k}\right)=\int_{V} W\left(\sigma_{i j}^{e}\right) d V-\int_{S} n_{j} \sigma_{i j}^{e} u_{i}^{k} d S-\int_{S_{\sigma}} n_{j} \bar{\sigma}_{i j} u_{i}^{k} d S
$$

with the subsidiary conditions: $u_{i}=\bar{u}_{i}$ on $S_{u}$,

$$
\sigma_{i j, j}+\bar{f}_{i}=0 \text { in } V
$$

where: $W\left(\sigma_{i j}^{e}\right)$ - complement strain energy density; $\sigma_{i j}$ - internal equilibrium stress field.

The hybrid elements based on the variation of (5.2) leads to a class named "metis displacement elements". We would like emphasize the fact that the displacement field $u^{k}$ that is defined only on the boundary in (5.2) must be the same as in (5.1). That means that the unisolvent condition has to be respective to priori.

\section{METIS DISPLACEMENT MODEL FOR THE GENERALIZED PLANE STRAIN PROBLEM}

The tension on the interface $S_{i}$ between two contiguous elements $\Omega_{e-}$ and $\Omega_{e+}$ of the partition $\Omega_{e}$ is:

$$
t(\sigma)=0 \quad \text { on } \quad S_{i} .
$$

In the technique of the hybrid displacement element, these conditions as well as the equilibrium boundary condition (4.4d) are released while introducing on the edge and the interfaces $S_{i}$ a field of Lagrange multipliers $u$. In the $2 D$ problem, the function (5.2) becomes:

$$
\Pi(\boldsymbol{\sigma}, \boldsymbol{u})=\sum_{e} \int_{\Omega_{e}} W(\boldsymbol{\sigma}) d \Omega-\sum_{i} \int_{S_{i}} \boldsymbol{u}^{T} \boldsymbol{t}(\boldsymbol{\sigma}) d S-\int_{\partial \Omega} \boldsymbol{u}^{T} \boldsymbol{t}(\boldsymbol{\sigma}) d S
$$

where: $W(\boldsymbol{\sigma})=\frac{1}{2} \sigma^{T} \boldsymbol{S}^{d} \boldsymbol{\sigma}+\boldsymbol{\sigma}^{T} \boldsymbol{\varepsilon}^{o}$.

This function can be broken up into a sum of elements:

$$
\Pi(\sigma, u)=\sum_{e} \Pi_{e}(\sigma, u) .
$$

We deduce: $\Pi_{e}(\boldsymbol{\sigma}, \boldsymbol{u})=\int_{\Omega_{e}}\left(\frac{1}{2} \sigma^{T} S^{d} \boldsymbol{\sigma}+\boldsymbol{\sigma}^{T} \boldsymbol{\varepsilon}^{o}\right) d \Omega-\int_{\partial \Omega_{e}} \boldsymbol{u}^{T} \boldsymbol{t}(\boldsymbol{\sigma}) d S$.

In the metis displacement element method, the displacement field is prolonged to the interior of each element in a continuous manner (unisolvent principle): This principle permits the transformation following: 


$$
\int_{\partial \Omega_{e}} \boldsymbol{u}^{T} \boldsymbol{t}(\boldsymbol{\sigma}) d S=\int_{\Omega_{e}}\left(\boldsymbol{\sigma}^{T} \mathrm{def} \mathbf{u}+\mathbf{u}^{T} \mathbf{e q u} \sigma\right) d \Omega .
$$

Taking account $(4.4 \mathrm{c})$, we obtain:

$$
\Pi_{e}(\boldsymbol{\sigma}, \mathbf{u})=\int_{\Omega_{\varepsilon}}\left(\frac{1}{2} \boldsymbol{\sigma}^{T} \mathbf{S}^{d} \boldsymbol{\sigma}+\boldsymbol{\sigma}^{T} \boldsymbol{\varepsilon}^{o}-\boldsymbol{\sigma}^{T} \text { def } \mathbf{u}\right) d \Omega .
$$

Consider the discretized displacement field: $\quad \mathbf{u}=\mathbf{N}(x) \mathbf{q}$

where: $\mathbf{q}$ is a nodal displacement vector and $\mathbf{N}(\mathrm{x})$ is a shape function matrix.

And the discretized stress field: $\quad \sigma=\mathbf{R}_{R}(x) \mathbf{h}_{e}$,

where: $\mathbf{h}_{e}$ is the stress parameter vector unknown of the element $\Omega_{e}$ and $\mathbf{R}_{R}(\mathrm{x})$ is a shape function matrix of stresses.

Introducing the discretized displacement and stress fields into (6.4), we get:

$$
\Pi_{e}\left(\mathbf{h}_{e}, \mathbf{q}\right)=\frac{1}{2} \mathbf{h}_{e}^{T} \mathbf{F}_{e} \mathbf{h}_{e}+\mathbf{h}_{e}^{T} \mathbf{v}_{e}^{o}-\mathbf{h}_{e}^{T} \mathbf{G}_{e}^{T} \mathbf{q}
$$

where: $\mathbf{F}_{e}=\int_{\Omega_{e}} \mathbf{R}_{R}^{T} \mathbf{S}^{d} \mathbf{R}_{R} d \Omega ; \mathbf{v}_{e}^{o}=\int_{\Omega_{e}} \mathbf{R}_{R}^{T} \varepsilon^{o} d \Omega ; \mathbf{G}_{e}=\int_{\Omega_{e}} \mathbf{B}^{T} \mathbf{R}_{R} d \Omega$, where: $\mathbf{B}(\mathrm{x})=\operatorname{def} \mathbf{N}(\mathrm{x})$ is the matrix that contains derivatives of shape functions.

The variational equation of $(6.7)$ with respect to $\mathbf{h}_{e}$ gives:

$$
\mathbf{F}_{e} \mathbf{h}_{e}+\mathbf{v}_{e}^{o}-\mathbf{G}_{e}^{T} \mathbf{q}=\mathbf{0} \Rightarrow \mathbf{h}_{e}=\mathbf{F}_{e}^{-1} \mathbf{G}_{e}^{T} \mathbf{q}-\mathbf{F}_{e}^{-1} \mathbf{v}_{e}^{o}
$$

Consider the total variation of structure in (6.2) with respect to nodal displacements by taking account (6.7):

$$
\sum_{e} \mathbf{g}_{e}=\sum_{e} \mathbf{G}_{e} \mathbf{h}_{e}=0
$$

where $\mathbf{g}_{e}$ is the generalized force of each element, with:

$$
\mathbf{g}_{e}=\mathbf{G}_{e} \mathbf{h}_{e}
$$

Replace $\mathbf{h}_{e 1}$ from (6.8) into (6.10), we have: $\mathbf{g}_{e}=\mathbf{K}_{e} \mathbf{q}-\mathbf{g}_{e}^{o}$, where: $\mathbf{K}_{e}=\mathbf{G}_{e} \mathbf{F}_{e}^{-1} \mathbf{G}_{e}^{T} ; \mathbf{g}_{e}^{o}=\mathbf{G}_{e} \mathbf{F}_{e}^{-1} \mathbf{v}_{e}^{o}$

Introducing (6.11) into (6.9), we obtain: $\mathbf{K q}=\mathbf{g}^{\circ}$, where: $\mathbf{K}=\sum_{e} \mathbf{K}_{e} ; \mathbf{g}^{o}=\sum_{e} \mathbf{g}_{e}^{o}$.

Resolving the equation system (6.12), we obtain the nodal displacements. The stress parameter vector $\mathbf{h}_{e}$ obtained by (6.8). The displacement and stress fields are calculated by the formula $(6.5)$ and $(6.6)$, respectively.

\section{EXAMPLE AND RESULTS}

Considering an equilateral triangular prismatic bar has the mechanical properties as following:

$$
E_{1}=E_{2}=E_{3}=30 \mathrm{MPa} ; G_{12}=G_{23}=G_{13}=12 \mathrm{MPa} ; \nu_{12}=\nu_{23}=\nu_{13}=0.25
$$


and the unitary torsion angle is $\theta$.
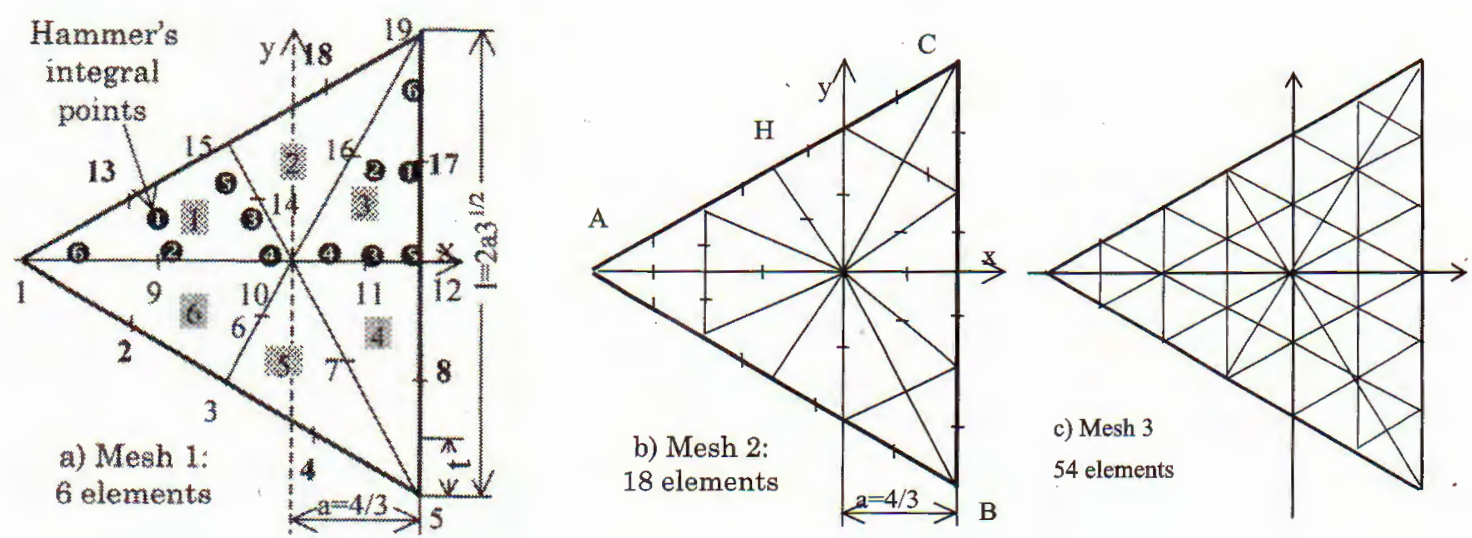

Fig. 2. Meshes of the structure

The displacements are deduced from (3.1) and (3.2):

$$
u(x, y)=0 ; v(x, y)=0 ; w(x, y)=\theta \psi .
$$

The cross-section of this structure is modelled by the metis displacement model with triangular elements in six nodes. The results obtained are compared with the exact results which are calculated by the analytical solution.

Three meshes with 6, 18 and 54 elements that named coarse, medium and fine mesh respectively are used (see in Fig. 2).

We present in table 1 the displacements in some points of the mesh 1 obtained by the present method in comparison with the exact results calculated by (7.1).

In the Figs. $3 \mathrm{a}$ and 3b, we compare the stresses calculated at Hammer's integral points in element 1 of the mesh 1 with the theoretical values obtained by (3.6).

The Figs. $3 \mathrm{a}$ and $3 \mathrm{~b}$ show that the stress curves in the metis method are very suitable to those in the analytical method.

The Fig. 4 presents the displacement $w$ at the 3 edges of the mesh 1 . We find that the displacement on the edges $A B$ and $B C$ is coincident. It is agreement with the analytical solution.

Table 1. Displacements in some points of the mesh 1

\begin{tabular}{|c|c|c|c|}
\hline $\begin{array}{c}\text { Point and } \\
\text { co-ordinates }\end{array}$ & $\begin{array}{c}\text { W } \\
\text { (analytical solution) }\end{array}$ & $\begin{array}{c}\text { W } \\
\text { (calculated value) }\end{array}$ & $\begin{array}{c}\text { Relative } \\
\text { error (\%) }\end{array}$ \\
\cline { 1 - 1 } All tops & 0.0 & 0.0 & 0.0 \\
\hline Pt $2(-5 / 3 ;-1 / \sqrt{3})$ & 0.57735032 & 0.400010 & 30.72 \\
\cline { 1 - 1 } $\operatorname{Pt~} 8(4 / 3 ;-2 / \sqrt{3})$ & $\operatorname{Pt~} 18(1 / 3 ; 3 / \sqrt{3})$ & & \\
\cline { 1 - 1 } $\operatorname{Pt~} 4(1 / 3 ;-3 / \sqrt{3})$ & -0.57735032 & -0.831670 & 44.05 \\
\cline { 1 - 1 } $\operatorname{Pt~} 13(-5 / 3 ; 1 / \sqrt{3})$ & & & \\
\hline
\end{tabular}




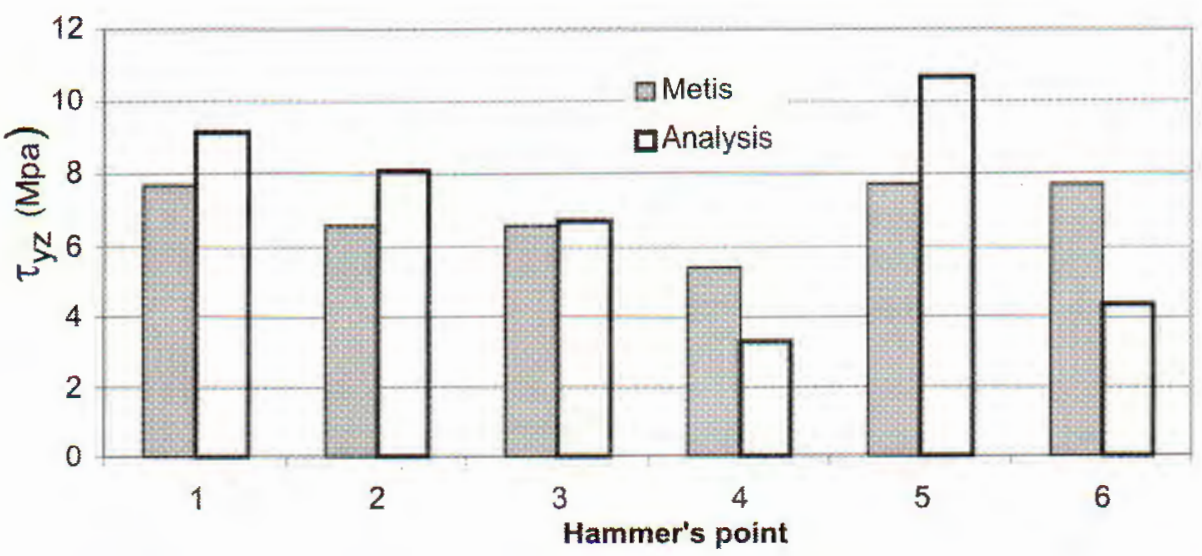

Fig. 3a. Stress $\tau_{y z}$ in the element 1 of the mesh 1

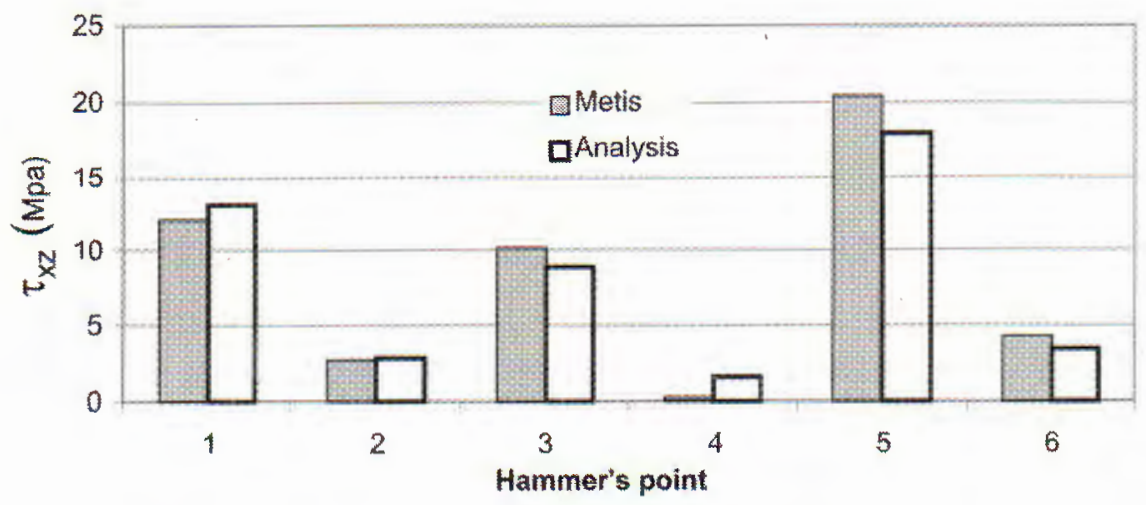

Fig. 3b. Stress $\tau_{x z}$ in the element 1 of the mesh 1

We find that the element number of the structure is still very small ( 6 elements) but the results obtained (displacements and stress) are close to the exact results.

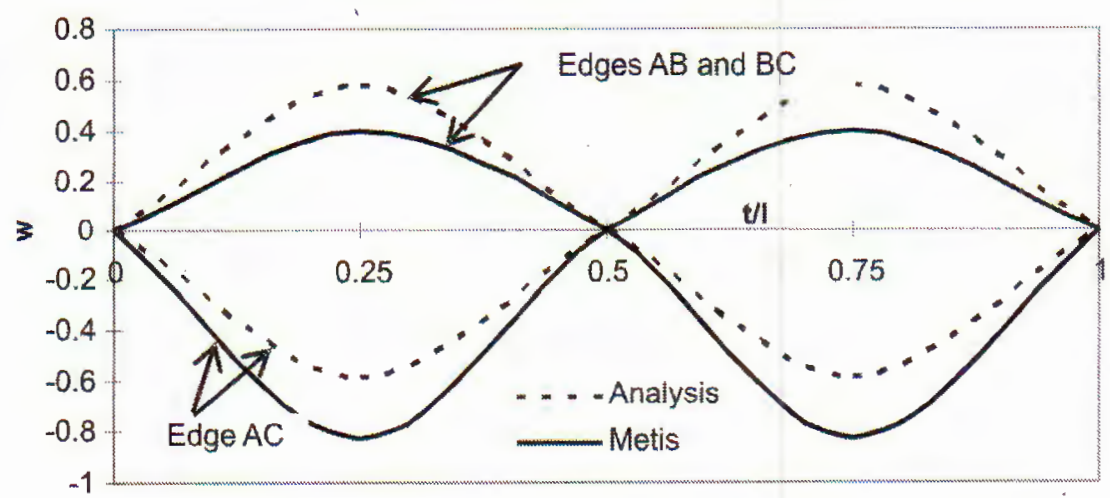

Fig. 4. Displacement $w$ at edges in mesh 1

To see the convergence of the solution, we consider the stresses at the 3 edges of the structure because the stresses at the edges are maximal. Considering the formula (3.6), we find that the stresses of the points which are symmetrical via axis $O x$ have the same 
values and in same sign for the component $\tau_{y z}$ and same value but in opposite sign for the component $\tau_{x z}$. The values obtained by the present method give also this result. Then, we see only the stresses at 2 edges $(A B$ and $B C)$.

The values of the stresses on these edges are showed on the Figs. 5 and 6 (where: $\mathrm{t}$ is the distance from a point on the edge $\mathrm{AB}$ or the edge $\mathrm{BC}$ to the point $\mathrm{A}$ or the point $\mathrm{B}$ respectively and $l$ is the length of the edge).

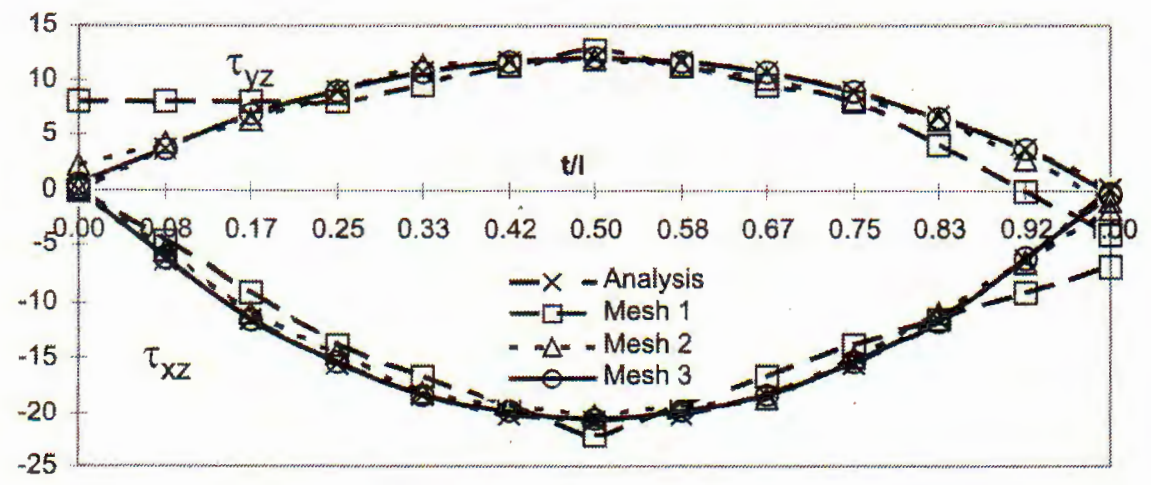

Fig. 5. Stresses $\tau_{y z}$ and $\tau_{x z}$ on the edge $A B$

The Fig. 5 indicates that on the edge $A B$, the stress $\tau_{x z}$ is dominant; and the stress $\tau_{y z}$ is significant. But on the edge $B C$, the stress $\tau_{x z}$ is equal zero in theoretically; and $\tau_{y z}$ becomes dominance (see Fig. 6).

The Figs. 5 and 6 also show that the results obtained in mesh 1 are rather gross, especially at the tops and near the tops of triangular section. The results of mesh 3 are coincides with those of the theory. But the results of mesh 2 are acceptable because their values are rather concordant with the values of analytical solution.

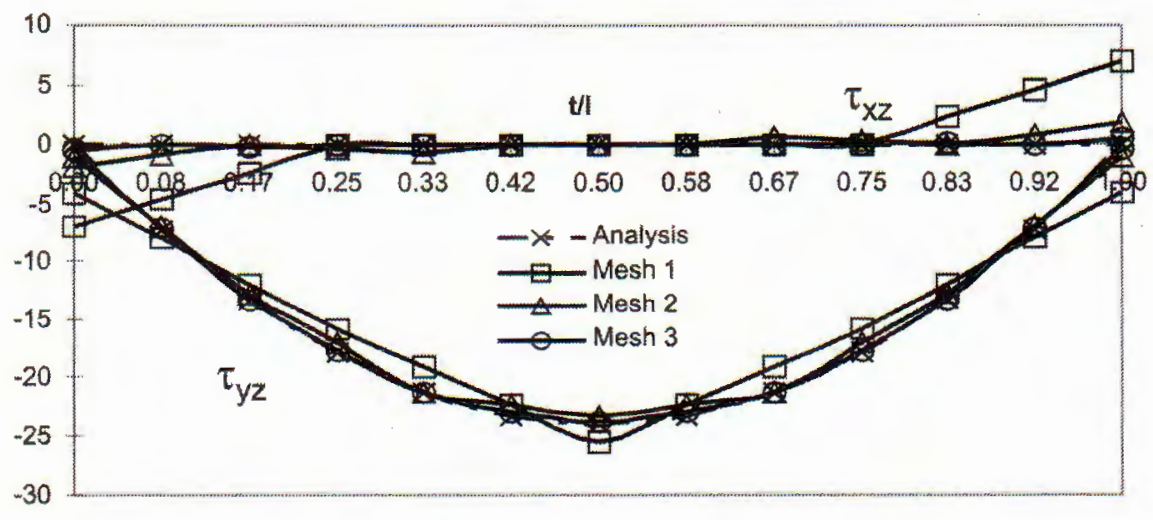

Fig. 6. Stresses $\tau_{y z}$ and $\tau_{x z}$ on the edge AB

\section{CONCLUSION}

Depend on the theory of generalized plane strain state of Lekhnitskii [1], the threedimensional problem $(3 D)$ was transformed into a problem $2.5 D$ whose geometry is of twodimensional and the displacement, strain and stress field of stress are three-dimensional. 
We find that there is a monotonic convergence of the solutions from mesh 1 to mesh 3. It means that the more the element number increases, the more the solution of the method present reaches the exact solution. In this problem with 18 elements (medium mesh), we can obtain the result very near with the exact result.

The results of the calculation of displacements and the stresses in the anti-plan mode by the metis element are very satisfied. The percentage of relative error to the theoretical solution is sometimes very large, but the absolute error remains always limited. The metis element, consequently, describes correctly in the anti-plan mode. So, the metis element model gives a new method to calculate and analyze structures.

\section{REFERENCES}

1. S. G. Lekhnitskii, Theory of Elasticity of an Anisotropic Body, Holden-day, San/Fransco, California, USA, 1963.

2. L. Solomon, Linear Elasticity (Élasticité Linéaire), Masson et Cie Éditeurs, 1968.

3. Nguyen Dang Hung, On the monotory and the convergence of a special class of hybred finite element: the mongrel element, Variational Methods in Mechanics of Solids, Ed. by S. Nemat-Nasser, Pergamon, 1978.

4. Nguyen Tien Duong and Nguyen Dang Hung, Stress singularity order in the delamination of a composite laminate, The $7^{\text {th }}$ National Congress on Mechanics, Hanoi December 18-21, 2002, Page 151-159.

5. Saxcé G.D., Design of a monolayer mongrel hybrid finite element for the modeling of the delamination in composite materials (Conception d'un élément fini hybride métis monocouche pour la modélisation du delaminage dans les matériaux composites), Rapport Interne du Service Mécanique des Matériaux et des Structures, Faculté Polytechnique de Mons, Programme Mobilisateur Multimatériaux, Octobre 1992.

Received June 17, 2005

Revised August 5, 2005

\section{SỬ DỤNG MÔ HİNH NGOẠI LAI ĐẶC BIỆT ĐẼ் GIẢI BÀI TOÁN XOÅN CƯA THANH LĂNG TRỤ}

Dựa trên lý thuyết đàn hồi của Lekhnitskii [1], các công thức cưa trạng thái biến dạng phẳng tổng quát cho bài toán xoăn của thanh lăng trụ được thiết lập. Từ đó bài toàn trong không gian 3 chiều (3D) được biển đổi thành bài toán 2,5 chiều $(2,5 \mathrm{D})$. Mô hình ngoại lai đặc biệt [3] là cầu nối giữ̛ các mô hình cổ điển một trường và mô hình ngoại lai hai trường. Các mô hình ngoại lai đặc biệt có các ưu điểm của các mô hình cổ điển và các mô hình ngoại lai: các tính chất đối ngẩu và hội tụ một cách đơn điệu của các mô hình thuần túy và sự hội tụ nhanh của các mô hình ngoại lai. Bài báo sử dụng mô hình chuyển vị ngoại lai đặc biệt để giải bài toán xoắn của thanh lăng trụ sau khi biển đổi bài toán tì̀ không gian 3D sang không gian 2.5D. Sự phù hợp của các kết quả tính toán được từ phương pháp này với lời giải chính xác băng phương pháp giải tích đã chì ra sự đúng đăn của mô hình mới. 